\title{
Exploring Physical and Social Wellness of High School Students in Suva, Fiji
}

\author{
Latileta Odrovakavula $^{1} \&$ Masoud Mohammadnezhad ${ }^{1}$ \\ ${ }^{1}$ School of Public Health \& Primary Care, Fiji National University, Suva, Fiji \\ Correspondence: Dr Masoud Mohammadnezhad, School of Public Health \& Primary Care, Fiji National \\ University, Fiji. Tel: 679-331-1700. E-mail: masoud.m@fnu.ac.fj
}

Received: October 26, 2021 Accepted: November 26, 2021 Online Published: December 10, 2021

doi:10.5539/gjhs.v14n2p8 URL: https://doi.org/10.5539/gjhs.v14n2p8

\begin{abstract}
Background: Given the characteristics of the adolescence life stage, the physical and social wellness dimensions remain a challenge. The aim of this study was to determine adolescent perceptions of physical and social wellness in secondary schools in Fiji.

Materials and Methods: Four purposively selected secondary schools in Suva, Fiji were part of this qualitative cross sectional study in 2019. Fijian students enrolled into years 11 to 13 in the selected schools were invited to participate. Participants were purposively sampled. Data was collected using a structured self-administered questionnaire. Descriptive statistics were generated through the Statistical Package for the Social Sciences software version 25 .

Results: A total of 350 high school students, with the mean age of $17.5(\mathrm{SD}= \pm 0.9)$, participated in the study. The majority (48\%) had very high scores for physical wellness and a fifth of the participants (28\%) had low scores. In terms of social wellness, about a third (28.9\%) scored low whilst the majority $(40.3 \%)$ had high scores of social wellness.

Conclusion: This study adds to the pool of knowledge for wellness increases chances of improvement in adolescent program development specifically in terms of physical and social wellness. Appropriate interventions are recommended to improve physical and social wellness in high school students in Fiji.
\end{abstract}

Keywords: high school students, Fiji, physical wellness, social wellness, wellness

\section{Introduction}

Key players in adolescent wellness have poured in efforts in adolescent health in the efforts of making adolescent wellbeing a central driver of healthy future populations. This is attributed to years of recognizing major diseases and injuries affecting the adolescent age groups (WHO, 2017). This is supported by the increasing adolescent population in parallel to the increase of social and health inequalities (Laski, 2015; Viner et al., 2018). The heightened population growth has also seen an increase in adolescent health issues including premature death, illnesses, and injuries (Azzopardi et al., 2016; WHO, 2017). In 2019 alone, there was an estimated 2.2 million death toll amongst children and youth, where $43 \%$ occurred amongst adolescents age 10-19, the majority died from preventable causes (Unicef, 2020; WHO, 2017).

Experts of adolescent wellbeing have called for the need to comprehensively assess adolescent wellness (Preskitt et al., 2015). For wellness to occur, a balance of several dimensions is required (Baldwin et al., 2017; Goss 2011). Fiji's wellness concept includes seven dimensions: social, spiritual, environmental, occupational, psychological, physical wellness and financial (MHMS, 2014). It is essential to explore these dimensions establishing predictor variables and their roles in health. Given the characteristics of the adolescence life stage, the physical and social wellness dimensions remain a challenge. Growth and development such as puberty is shaped by both social and biological processes highlighting the need to study the twodimensions (Backes, 2019).

Wellness Fiji concept defined physical wellness as maintaining a state of biological good health and freedom from diseases (MHM, 2015). Literature defines physical wellness as an individual's level of physical activity, their nutrition and health behavior (Baldwin, 2017). Literature on association of physical activity and health is widely available, documenting benefits of physical fitness on the human body in reducing disease development and preventing or hindering disease progression (Warburton \& Bredin, 2017). These include reduction of health risks 
such as obesity, cardiovascular diseases, improving psychological health and quality of life and increasing longevity (Nuzum, 2020; Fletcher, 2018). The role of nutrition on physical wellness have long been explored and research conducted in Fiji have highlighted nutritional concerns such as the poor dietary patterns amongst adolescent (Wate et al., 2013). These included the high consumption of sugar-sweetened beverages, snacks high in fat, salt or sugar whilst there was an overall low intake of fruits and vegetables. The use and abuse of substances (smoking, drugs and alcohol) have been a World Health Organization (WHO) concern for years, let alone the use amongst adolescents (WHO, 2017). Substance use disorders (cancers, heart disease, mental conditions; bipolar disorder, anxiety disorder and personality disorder) peaks during adulthood because of drug use during the adolescence years (Schulte, 2014). Previous studies conducted in Fiji have highlighted concerns of substance use for students and youths (Puamau et al., 2011; WHO, 2016).

Wellness Fiji concept defines social wellness as the ability to maintain a positive, productive community (MHMS, 2015). Adolescent lives are influenced by social wellness factors including care and support, the level of care and support an adolescent receives from their parents influence their wellness (Peters et al., 2019; Bellis et al, 2017). Social wellness is also supported by relationships beyond an individual's family. Peer support has been determined to increase life satisfaction and these relations are resources to an individual and can assist in one's social support mechanism, performance and wellbeing (Jolly, Tamir, Burum, \& Mitchell, 2019; Puschner et al., 2019).

Adolescents enrolled into high schools receive some form of social support from the school environment indicating the role of school support in student social-emotional functioning (Bergunder et al., 2014; Dudovitz et al., 2017). Literature also indicate the negative impacts of social relations. These include conflicts, losses and demands (Walen \& Lachman, 2000). An individual's social network determines one's wellbeing.

Limited research work is available on adolescent wellness in Fiji. Well informed adolescent wellness programs and interventions required data. Therefore, this paper aims to determine adolescent perceptions of physical and social wellness in secondary schools in Fiji.

\section{Materials \& Methods}

\subsection{Study Design and Setting}

A cross-sectional study was conducted in a period of 2 months in 2019 amongst Secondary Schools in the Suva and the greater Suva areas, Fiji. Suva being the capital of Fiji, is the most urbanized and population dense area in the country. It is home to approximately, 287,000 people as stated on the 2017 population census (Fiji Bureau of Statistics, 2018). Suva is also the central business district of the country and contains the main trading port.

Schools selection was based on a two stage cluster random sampling where the geographical locations of the schools was considered as the first cluster. Four municipalities were identified: Suva, Lami, Nasinu and Nausori. The second cluster classified schools into urban and peri-urban schools. Fiji's Ministry of Education, Heritage and Arts (MoEHA) provided a school list specifying school locations. Purposive selection of four schools were made, considering both urban and peri-urban schools were represented as well as the representation of religion, ethnicity and gender groups.

\subsection{Study Sample}

Sample size was calculated using the population proportion sample size calculator. A $50 \%$ likelihood of adolescent wellness perception, at a $95 \%$ confidence interval, a $5 \%$ non-respondent rate and a $5 \%$ margin error were considered (Suresh \& Chandrashekara, 2012). The total number of secondary school student's population in Suva is approximately 30,281 (MoEHA, 2019). A sample size of 380 was required, with consideration made to a 5\% non-respondent rate, a sample size of 400 students was considered.

\subsection{Data Collection Tool}

The study used a structured self-administered questionnaire to establish physical and social wellness perceptions. Questions were sourced and modified from similar physical and social wellness studies. Spurr (2009) and Goodwin (2009) had 64 and 36 items, respectively, these were related to adolescent wellness. Social and physical wellness items were selected to develop this study's research tool.

Three sections were developed for this study's questionnaire: demographic (5 questions), adolescent physical wellness (12 questions) and adolescent social wellness (10 questions). Adolescent perceptions were measured using a five point Likert scale. Scores ranged from 5 to 1 where 5 was strongly agree and 1 was strongly disagree. Scoring was reversed for negative worded statements.

English was commonly used in the selected study sites therefore, questionnaires were printed in the English language. Experts of public health reviewed the questionnaire testing content validity, this ensured alignment of 
content to the study's aim and objectives. Cronbach alpha was calculated to test for reliability, this indicated an internal satisfactory internal consistency $(\alpha=0.92)$.

\subsection{Study Procedure}

Once schools were selected, arrangements were made for school visits, seeking student participation. To facilitate research activities communication a focal person was appointed in each school. Students were verbally introduced to and informed about the study. An information sheet briefly explained the purpose of the study. The self administered questionnaire was distributed to students who met the inclusion criteria. For those below 18 years of age, parental consent was obtained. The consent forms were available in the English, Itaukei and Hindi languages. Assent forms were also provided to all participating students. Students took approximately 20 to 30 minutes to fill the questionnaire, principal researcher was available during data collection to provide clarifications when needed. Answered questionnaires were collected directly after completion.

\subsection{Data Management and Analysis}

Data was entered and managed through Microsoft excel. Statistical Package for the Social Science (SPSS), version 25 was used to conduct descriptive analysis.

\subsection{Ethical Considerations}

Ethical approval was obtained from the Fiji National's University's (FNU), CMNHS Heath Research Ethics Committee (CHREC). The MoEHA Research and Development section provided Facility approval. Before collecting data, parental consent was sort for participants below 18 years.

\section{Results}

\subsection{Demographic Characteristics of Participants}

Table 1 presents socio demographic characteristics of the study participants. A total of 350 high school students aged between 16 to 20 years (mean age $17.5, \mathrm{SD}= \pm 0.9$ ) participated in the study. There were more female participants $(60.9 \%)$ and Itaukei students $(58.6 \%)$ in comparison to other races. About half of the participants (46\%) were enrolled into the Year 12 level. In terms of family income, data indicated that the majority of the families had an annual income below $\$ 5,000$ (23.4\%) and between $\$ 10,000-\$ 20,000$ (22\%).

Table 1. Socio-demographic characteristics of participants $(n=350)$

\begin{tabular}{lll}
\hline Characteristics & Frequency (n) & Percentage (\%) \\
\hline Age (Mean \pm SD) & $17.5 \pm 0.9$ & \\
Gender & 137 & 39.1 \\
Male & 213 & 60.9 \\
Female & & \\
\hline Age & 87 & 24.9 \\
16 years old & 239 & 68.3 \\
17 -18years old & 24 & 6.9 \\
$19-20$ years old & & \\
\hline Ethnicity & 205 & 58.6 \\
Itaukei & 118 & 33.7 \\
Indo-Fijian & 27 & 7.7 \\
Others & 111 & 31.7 \\
\hline Education Level & 161 & 46.0 \\
Years 11 & 78 & 22.3 \\
Years 12 & 82 & 23.4 \\
Years 13 & &
\end{tabular}




\begin{tabular}{lll}
\hline$\$ 5000-\$ 10,000$ & 57 & 16.3 \\
$\$ 10,000-\$ 20,000$ & 77 & 22.0 \\
$\$ 30,000-40,000$ & 54 & 15.4 \\
$\$ 40,000-\$ 50,000$ & 25 & 7.1 \\
Above $\$ 50,000$ & 24 & 6.9
\end{tabular}

Table 2 presents the 12 statements used to assess students' perceptions of the physical wellness. These statements were nutrition, weight, physical activity and substance use. In terms of physical weight, the majority of participants perceived themselves to be physically well (88\%) and having a normal weight (72\%). In terms of nutrition, about half of the students believed they consume balanced diet (52.3\%). Less than half of the students, $(47.2 \%)$, either agreed or strongly agreed to the statement of weight influencing physical wellness. For physical activity, a high percentage agreed or strongly agreed (97.1\%) that physical activity was important. About $93.5 \%$ of the students, perceived themselves to be able to do some form of physical activity.

For substances use, the majority of the students either agreed or strongly agreed that behaviors such as drinking kava (86\%), smoking marijuana (92.2\%), sniffing glue (96\%), using hard drugs $(95.4 \%)$ and the consumption of alcohol $(87.7 \%)$ were harmful to their health. The majority of the participants $(82 \%)$ agreed or strongly agreed that physical development (body weight, nutrition, physical activity, smoking, drugs, kava and alcohol) contributes to their overall sense of wellness.

Table 2. Participants' response to physical wellness related statements

\begin{tabular}{|c|c|c|c|c|c|}
\hline \multirow{4}{*}{ Physical wellness related statements } & \multicolumn{5}{|c|}{ Frequency $(\%)$} \\
\hline & \multicolumn{3}{|l|}{ Strongly } & \multirow{3}{*}{\multicolumn{2}{|c|}{$\begin{array}{l}\text { Strongly } \\
\text { Disagree } \\
\text { Disagree }\end{array}$}} \\
\hline & Agree & $\&$ & Neutral & & \\
\hline & Agree & & & & \\
\hline I am physically well. & $308(88)$ & & $35(10)$ & $7(2)$ & \\
\hline I have a healthy normal weight. & $252(72)$ & & $35(18.6)$ & $33(9.4)$ & \\
\hline My weight affects my physical development. & $165(47.2)$ & & $77(22.0)$ & $108(30.9)$ & \\
\hline I eat a balanced diet. & $183(52.3)$ & & $112(32.0)$ & $55(15.8)$ & \\
\hline Physical activity is important. & $340(97.1)$ & & $6(1.7)$ & $4(1.2)$ & \\
\hline I am capable of doing some form of physical activity. & $327(93.5)$ & & $16(4.6)$ & $7(2)$ & \\
\hline Drinking Kava affects my health. & $301(86)$ & & $34(9.7)$ & $15(4.3)$ & \\
\hline Marijuana affects my health. & $323(92.2)$ & & $13(3.7)$ & $14(4)$ & \\
\hline Sniffing glue or Solvents affects my health. & $336(96)$ & & $3(0.9)$ & $11(3.1)$ & \\
\hline $\begin{array}{l}\text { Using drugs such as Cocaine, Heroin, Ecstasy, and Crystal Meth affects } \\
\text { my health. }\end{array}$ & $334(95.4)$ & & $6(1.7)$ & $10(2.9)$ & \\
\hline $\begin{array}{l}\text { Drinking anything with alcohol such as beer, wine or liquor, homebrew } \\
\text { affects my health. }\end{array}$ & $307(87.7)$ & & $20(5.7)$ & $23(6.6)$ & \\
\hline $\begin{array}{l}\text { Physical Development (body weight, nutrition, physical activity, } \\
\text { smoking, drugs, kava and alcohol) contributes to my overall sense of } \\
\text { wellness. }\end{array}$ & $287(82)$ & & $27(7.7)$ & $36(10.2)$ & \\
\hline
\end{tabular}

Table 3 summarizes descriptive analysis of the social wellness related items. Ten statements were used to assess students' perception of social wellness. These statements were related to the definition of social wellness, the perception of being socially well and social support from family, friends and from school.

In terms of knowing the definition of social wellness, $78.8 \%$ agreed or strongly agreed to the statement, "I know what social wellness means". Most of the participants (82.3\%) perceived themselves to be socially well. About $93.1 \%$ agreed or strongly agreed to their families providing them with support and $97.1 \%$ perceived their parents 
or guardians to be nurturing, warm and accepting. Similar high percentages were observed for perception of friends' social support, $86.9 \%$ felt connected to their friends. In terms of social support in a school context, $74.6 \%$ felt that the people in their school care about for them and $84.9 \%$ agreed or strongly agreed to receiving support from teachers and school counselors. The majority (88\%) agreed that social development (coping skills, parents, friends, and school) contributes to their overall sense of wellness.

Table 3. Participants' response to social wellness related statements

\begin{tabular}{llll}
\hline \multirow{2}{*}{ Social wellness related statements } & Frequency (\%) & \\
\cline { 2 - 4 } & $\begin{array}{l}\text { Strongly Agree } \\
\text { \& Agree }\end{array}$ & Neutral & $\begin{array}{c}\text { Strongly Disagree } \\
\text { \& Disagree }\end{array}$ \\
\hline I know what social wellness means. & $276(78.8)$ & $60(17.1)$ & $14(4)$ \\
\hline I am socially well. & $288(82.3)$ & $52(14.9)$ & $10(2.9)$ \\
\hline My Family at home supports me. & $326(93.1)$ & $18(5.1)$ & $6(1.7)$ \\
\hline My parent/guardian is nurturing, warm and accepting. & $321(91.7)$ & $21(6.0)$ & $8(2.3)$ \\
\hline $\begin{array}{l}\text { My parent/guardian takes interest in where I am, whom I am with, and } \\
\text { what I am doing. }\end{array}$ & $318(90.8)$ & $21(6.0)$ & $11(3.2)$ \\
\hline I feel connected to my friends & $304(86.9)$ & $35(10.0)$ & $11(3.1)$ \\
\hline I receive support from my teachers and school counselors. & $297(84.9)$ & $36(10.3)$ & $17(4.8)$ \\
\hline I feel that the people in my school care about me. & $261(74.6)$ & $73(20.9)$ & $16(4.6)$ \\
\hline I receive support from my youth group. & $265(75.7)$ & $65(18.6)$ & $20(5.7)$ \\
\hline $\begin{array}{l}\text { Social development (parents, friends, and school) contributes to my } \\
\text { overall sense of wellness. }\end{array}$ & $308(88)$ & $30(8.6)$ & $12(3.4)$ \\
\hline
\end{tabular}

\subsection{Levels of Physical and Social Wellness}

Descriptive analysis of wellness scores found that nearly half of the participants $(48.3 \%)$ had very high physical wellness scores, about a fifth (23.7\%) scored high scored whilst another $28.9 \%$ had scored low. In terms of social wellness scores, the majority (40.3\%) scored very high scores and around a third (30.9\%) of the students had high scores. There were $28.9 \%$ of the participants who had low social wellness levels.

\section{Discussion}

Similar results between this study and literature was expected. However, this study adds to literature as it provides important research findings on adolescent wellness to Fiji's health sector, its policy makers and program developers. Discussion begins with an overview of adolescent perceptions of physical wellness.

The perception of physical wellness and its related factors are further explored in the survey. Quantitative results indicated the high number of participants that perceived themselves to be physically well. In terms of weight, nearly two thirds of the participants agreed to have a normal weight and about a third of the participants disagreed or strongly disagreed that weight influenced their physical development. This highlights the need to educate on the influence of weight on physical wellness as prevalence of weight related health issues such as obesity have increased over the years and remains a concern for Fiji (Lin et al., 2016; Mavoa \& McCabe, 2008).

In terms of nutrition, findings indicated that $52.3 \%$ perceived themselves to consume healthy balanced diet. This may potentially indicate the low level of consumption of balanced diet. Poor diet has been a concern for Fiji as per previous studies (Wate et al., 2013). Nutritional related studies conducted in the Pacific highlight the need to consider socioeconomic and cultural factors that are found to influence eating pattern of people in the Pacific (Mavoa \& McCabe, 2008). Past studies have also indicated the shift from the consumption of a traditional diet to the high consumption of refined food high in fat, sugar and salt, this nutritional transition exist on high levels in the Pacific (Sievert et al., 2019).

In terms of substance use results found that students perceived, use of substances affected their health. These substances practices ranged from kava consumption, marijuana use, sniffing glue or solvents and the consumption 
of alcohol, the descriptive percentages ranged from $86 \%$ to $96 \%$. Awareness on substance use amongst adolescents will be required to influence perceptions of students who thought otherwise. Results may indicate the high sense of the influence of substances on health however; the level of practice amongst adolescents needs to be explored as part surveys have indicated concerns for the increase in use of substances amongst school students (WHO, 2016).

Results of this study indicated low perception levels of being socially well. This may indicate the need to educate high school students of wellness and its dimensions. Results also indicated that high school students receive social support via three main groups; family, friends and school support. Support was perceived to be received from home where parents/guardians are nurturing, warm and accepting. The majority felt connected to their friends and perceived that support was received from school and youth groups. These high percentages may potentially indicate the level of social support participants receive. Such support tends to benefit individuals; these include social support as protective factors, developing self-esteem and emotional functioning (Camara et al., 2017). For adolescents receiving support from friends and family have been studied to be superior to other types of support. Therefore, adolescent wellness program developers are take this factors into considerations (Griffiths et al., 2011).

For this study, the majority of the participants had very high or high wellness scores. Similar results were found in other adolescent wellness studies (Preskitt et al., 2015). High wellness scores could be attributed to several factors. These include within and beyond the school environment. For factors within the school environment, these include provision of school programmes pertaining to physical activity such as obesity prevention programs, physical education classes, availability of nutritional food, wellness school policies encompassing both student and teachers' well-being and health related curriculum (Lever et al., 2017).

Findings of this study indicated that about a third of the participants had low levels of physical and social wellness. Low scores may be due to the lack of social support from families, expectations placed on adolescents both socially and academically and the long hours spend online. These factors have also been indicated by previous studies to contribute to low levels of wellness (Berk, 2012).

\subsection{Limitations}

This study would have been ideal if data on wellness practice was also collected. A comparison between perception and practice would have provided further understanding into adolescent wellness. This finding may not be generalized to all of Fiji's adolescent population due to the sample being limited to adolescents enrolled into high schools.

\section{Conclusions}

Wellness occurs when there is a balance between dimensions. This study adds to the pool of knowledge for wellness \& increases chances of adolescent programs improvement and development specifically in terms of physical and social wellness. Adolescent wellness programs are to consider factors discussed as barriers and supportive factors for physical and social wellness. Targeting adolescent wellness in schools maybe beneficial for adolescent wellbeing. Given the limited studies conducted on physical and social wellness in Fiji and the Pacific, further studies needs to be conducted in these areas. Expansion of study sites to include more schools should be considered in future research. Appropriate interventions are recommended to improve physical and social wellness in high school students in Fiji.

\section{Acknowledgements}

The authors thank all the participants, teachers, and schools for their enthusiastic participation in this study.

\section{Competing Interests Statement}

The authors declare that there are no competing or potential conflicts of interest.

\section{References}

Azzopardi, P. S., Hearps, S. J. C., Francis, K. L., Kennedy, E. C., Mokdad, A. H., Kassebaum, N. J., ... Patton, G. C. (2016). Articles Progress in adolescent health and wellbeing: tracking 12 headline indicators for 195 countries and territories, 1990-2016. The Lancet, 393(10176), 1101-1118. https://doi.org/10.1016/S0140-6736(18)32427-9

Backes. (2019). Adolescent development. The Promise of Adolescence: Realizing Opportunity for All Youth. Retrieved September 23, 2020, from https://www.ncbi.nlm.nih.gov/books/NBK545476/

Baldwin, D. R., Towler, K., Oliver, M. D., \& Datta, S. (2017). An examination of college student wellness: A research and liberal arts perspective. Health psychology open, 4(2), 2055102917719563. https://doi.org/10.1177/2055102917719563 
Bellis, M. A., Hardcastle, K., Ford, K., Hughes, K., Ashton, K., Quigg, Z., \& Butler, N. (2017). Does continuous trusted adult support in childhood impart life-course resilience against adverse childhood experiences - a retrospective study on adult health-harming behaviours and mental well-being. BMC psychiatry, 17(1), 110. https://doi.org/10.1186/s12888-017-1260-z

Bergunder, M., Levy, G., Razin, R., Spencer-oatey, H., Frazer, G., Bough, T. G., ... Noh, M. S. (2014). What is spirituality? A personal exploration. Nursing Management (Harrow, London, England : 1994), 23(6), 39-52. https://doi.org/10.1108/17570981111193547

Berk, L. E. (2012) Cognitive development in adolescence. In Infants, Children, and Adolescents (7th ed., J. Mosher, pp. 564-597). Ally-Bacon, Boston, MA, USA.

Camara, M., Bacigalupe, G., \& Padilla, P. (2017). The role of social support in adolescents: are you helping me or stressing me out? International Journal of Adolescence and Youth, 22(2), 123-136. https://doi.org/10.1080/02673843.2013.875480

Dudovitz, R. N., Chung, P. J., \& Wong, M. D. (2017). Teachers and Coaches in Adolescent Social Networks Are Associated With Healthier Self-Concept and Decreased Substance Use. The Journal of school health, 87(1), 12-20. https://doi.org/10.1111/josh.12462

Fiji Bureau of Statistics. (2018). 2017 Population and Housing Census. Retrieved from file:///C:/Users/latileta.o/Downloads/2017_Population_and_Housing_Census_Release_1.pdf

Fletcher, G. F., Landolfo, C., Niebauer, J., Ozemek, C., Arena, R., \& Lavie, C. J. (2018). Promoting Physical Activity and Exercise: JACC Health Promotion Series. Journal of the American College of Cardiology, 72(14), 1622-1639. https://doi.org/10.1016/j.jacc.2018.08.2141

Goodwin, I. C. (2009). The Relationship betwen Perceived Wellness and Stages of Change for Exercise among Rural African American Women. Retrieved https://scholarworks.gsu.edu/cgi/viewcontent.cgi?referer=https://www.google.com/\&httpsredir=1\&article= $1008 \&$ context $=$ nursing_diss

Goss, H. B. (2011). Wellness education: An integrated theoretical framework for fostering. Transformative Learning, 3904.

Griffiths, K. M., Crisp, D. A., Barney, L., \& Reid, R. (2011). Seeking help for depression from family and friends: A qualitative analysis of perceived advantages and disadvantages. BMC Psychiatry, 11(1), 196. https://doi.org/10.1186/1471-244X-11-196

Jolly, E., Tamir, D. I., Burum, B., \& Mitchell, J. P. (2019). Wanting without enjoying: The social value of sharing experiences. PloS one, 14(4), e0215318. https://doi.org/10.1371/journal.pone.0215318

Laski, L. (2015). Realising the health and wellbeing of adolescents. BMJ (Online), 351, 15-18. https://doi.org/10.1136/bmj.h4119

Lever, N., Mathis, E., \& Mayworm, A. (2017). School Mental Health Is Not Just for Students: Why Teacher and School Staff Wellness Matters. Report on Emotional \& Behavioral Disorders in Youth, 17(1), 6-12. Retrieved from http://www.ncbi.nlm.nih.gov/pubmed/30705611\%0Ahttp://www.pubmedcentral.nih.gov/articlerender. fcgiz?artid=PMC6350815

Lin, S., Tukana, I., Linhart, C., Morrell, S., Taylor, R., Vatucawaqa, P., Magliano, D. J., \& Zimmet, P. (2016). Diabetes and obesity trends in Fiji over 30 years. Journal of Diabetes, 8(4), 533-543. https://doi.org/10.1111/1753-0407.12326

Mavoa, H. M., \& McCabe, M. (2008). Sociocultural factors relating to Tongans' and Indigenous Fijians' patterns of eating, physical activity and body size. Asia Pacific Journal of Clinical Nutrition, 17(3), 375-384. https://doi.org/10.6133/apjen.2008.17.3.03

Ministry of Health and Medical Services. (2014). The Wellness Fiji Conceptual Framework.

Ministry of Health and Medical Services. (2015). Fiji National Wellness Policy, 2015. Retrieved from https://www.health.gov.fj/wp-content/uploads/2018/03/National-Wellness-Policy-for-Fiji.pdf

Nuzum, H., Stickel, A., Corona, M., Zeller, M., Melrose, R. J., \& Wilkins, S. S. (2020). Potential Benefits of Physical Activity in MCI and Dementia. Behavioural neurology, 2020, 7807856. https://doi.org/10.1155/2020/7807856

Peters, I., Handley, T., Oakley, K., Lutkin, S., \& Perkins, D. (2019). Social determinants of psychological wellness 
for children and adolescents in rural NSW. BMC public health, 19(1), 1616. https://doi.org/10.1186/s12889-019-7961-0

Preskitt, J. et al. (2015). Wellness among US adolescents ages 12-17 years. Child Care Health Dev., 41, 1207-15. https://doi.org/10.1111/cch.12248

Puamau, E. S., Roberts, G., Schmich, L., \& Power, R. (2011). Drug and alcohol use in Fiji: a review. Pacific health dialog, 17(1), 165-171.

Puschner, B., Repper, J., Mahlke, C., Nixdorf, R., Basangwa, D., Nakku, J., .. \& Slade, M. (2019). Using peer support in developing empowering mental health services (UPSIDES): Background, rationale and methodology. Annals of Global Health, 85(1), 1-10. https://doi.org/10.5334/aogh.2435

Schulte, M. T., \& Hser, Y. I. (2014). Substance Use and Associated Health Conditions throughout the Lifespan. Public health reviews, 35(2). https://doi.org/10.1007/BF03391702

Sievert, K., Lawrence, M., Naika, A., \& Baker, P. (2019). Processed foods and nutrition transition in the pacific: Regional trends, patterns and food system drivers. Nutrients, 11(6). https://doi.org/10.3390/nu11061328

Spur, S. (2009). Student Perceptions of Adolescent Wellness. A Dissertation Submitted to the College of Graduate Studies and Research in Partial Fulfillment of the Requirements for the Degree of Doctor of Philosophy. Retrieved from https://core.ac.uk/download/pdf/55299755.pdf

Suresh, K., \& Chandrashekara, S. (2012). Sample size estimation and power analysis for clinical research studies. Journal of human reproductive sciences, 5(1), 7-13. https://doi.org/10.4103/0974-1208.97779

UNICEF. (2020). Mortality among children, adolescents and youth aged 5-24. Retrieved from https://data.unicef.org/topic/child-survival/child-and-youth-mortality-age-5-24/

Viner, R., Hargreaves, D., Varnes, L., Heys, M., \& Viner, R. (2018). The social determinants of young people 's health. June.

Walen, H. R., \& Lachman, M. E. (2000). Social support and strain from partner, family, and friends: Costs and benefits for men and women in adulthood. Journal of Social and Personal Relationships, 17(1), 5-30. https://doi.org/10.1177/0265407500171001

Warburton, D., \& Bredin, S. (2017). Health benefits of physical activity: a systematic review of current systematic reviews. Current opinion in cardiology, 32(5), 541-556. https://doi.org/10.1097/HCO.0000000000000437

Wate, J. T., Snowdon, W., Millar, L., Nichols, M., Mavoa, H., Goundar, R., Kama, A., \& Swinburn, B. (2013). Adolescent dietary patterns in Fiji and their relationships with standardized body mass index. International Journal of Behavioral Nutrition and Physical Activity, 10, 1-12. https://doi.org/10.1186/1479-5868-10-45

World Health Organization [WHO]. (2016). Fiji Islands Global School-based Student Health Survey Fiji Islands. $4,4-9$.

World Health Organization [WHO]. (2017). Global Accelerated Action for the Health of Adolescents (AA-HA!): guidance to support country implementation. Retrieved from file://C:/Users/TEMP.DESKTOP-3H1NQJG.000.001.002/Downloads/9789241512343-eng.pdf

World Health Organization [WHO]. (2017). More than 1.2 million adolescents die every year, nearly all preventable. https://www.who.int/news/item/16-05-2017-more-than-1-2-million-adolescents-die-everyyear-nearly-all-preventable

\section{Copyrights}

Copyright for this article is retained by the author(s), with first publication rights granted to the journal.

This is an open-access article distributed under the terms and conditions of the Creative Commons Attribution license (http://creativecommons.org/licenses/by/4.0/). 